\title{
O DESAFIO DA PROFISSÃO DE PROFESSOR NO BRASIL: ANÁLISE AVALIATIVA DA LINGUAGEM EM UM ARTIGO DE OPINIÃO
}

\section{THE CHALLENGE OF BEING A TEACHER IN BRAZIL: AN EVALUATIVE ANALYSIS OF LANGUAGE IN AN OPINION ARTICLE}

\author{
Ana Paula Carvalho Schmidt \\ Universidade Federal de Santa Maria \\ Santa Maria, Rio Grande do Sul, Brasil \\ Anidene de Siqueira Cecchin \\ Universidade Federal de Santa Maria \\ Santa Maria, Rio Grande do Sul, Brasil \\ Nédilã Espindola Chagas \\ Universidade Federal de Santa Maria \\ Santa Maria, Rio Grande do Sul, Brasil \\ Sara Regina Scotta Cabral \\ Universidade Federal de Santa Maria \\ Santa Maria, Rio Grande do Sul, Brasil
}

RESUMO: Este trabalho apresenta uma análise, tendo por base o sistema de avaliatividade (MARTIN; WHITE, 2005), de um artigo de opinião acerca do desafio de ser professor no Brasil, veiculado na mídia,. Primeiramente, realizamos a análise contextual do artigo de opinião, enfocando as variáveis de registro (campo, relações e modo) do texto e identificamos quais tipos de avaliações são evidenciadas a partir das escolhas linguísticas do autor. A seguir, descrevemos os resultados de nossa análise a partir das avaliações de atitude (apreciação e julgamento de capacidade) e gradação (intensificação e quantificação), mostradas no texto em relação à profissão docente. Os resultados evidenciaram a organização do texto conduzida por questionamentos, o uso de apreciações e de julgamento de estima social para, respectivamente, demonstrar a qualificação e a avaliação do professor, bem como o uso de gradações de intensificação a fim de reforçar a opinião do autor.

PALAVRAS-CHAVE: Sistema de Avaliatividade; Artigo de Opinião; A profissão professor.

ABSTRACT: This work presents an analysis of an opinion article about the challenges of being a teacher in 
Brazil nowadays. Our methodological approach is the Appraisal System (MARTIN; WHITE, 2005). First, the contextual analysis was conducted, focusing on the register variables (field, tenor and mode). We also focused on how evaluations of attitude, judgement and graduation are made through the lexical choices of the author. Finally, we identified the views regarding teachers construed in the text, using resources of attitude (appreciation), judgement of capacity and graduation (intensification and quantification). The results evidenced a text organization focused on questioning, the use of appreciation and social esteem judgement for, respectively, the qualification and evaluation of teachers as well as graduation - intensification to reinforce the opinion of the author.

KEYWORDS: Appraisal System; Opinion Article; Teaching career. 


\section{INTRODUÇÃO}

A profissão de professor é um desafio para todos que pretendem seguir a carreira, haja vista as adversidades enfrentadas tais como a pouca procura pelos cursos de licenciatura ${ }^{1}$, as condições de infraestrutura das escolas públicas, a remuneração dos professores da rede pública de ensino (PEREIRA JUNIOR, 2016), o baixo desempenho em indicadores internacionais alcançados pelos estudantes (OECD, 2016, p. 48), entre outros. Diante dessa problemática, há uma grande cobrança relacionada à qualidade do ensino, em muitos casos vinculando essa à capacitação profissional do professor. Notícias e artigos que exploram essa temática têm sido publicados na tentativa de responsabilizar uma das partes envolvidas no processo, o que é preocupante para todos. Um bom exemplo disso é o artigo publicado no site de uma revista de grande circulação na mídia com o título de Ainda sobre os desafios de ser professor no Brasil, escrito por João Batista Araújo Oliveira. $\mathrm{O}$ autor em questão é considerado referência no âmbito educacional por sua formação e atuação em órgãos públicos e, no artigo selecionado, busca discutir acerca da qualidade do professor como requisito para o sucesso do aluno ao longo dos tempos.

A partir de uma perspectiva sistêmico-funcional, a linguagem se constitui como um sistema sociossemiótico de produção de significados em um determinado contexto (HALLIDAY; HASAN, 1985, HALLIDAY; MATTHIESSEN, 2014). Nesse sentido, é necessário discutir como a profissão docente é abordada com base nas escolhas linguísticas realizadas pelo autor do texto e quais interpretações podem ser evidenciadas. Essa abordagem justifica-se porque, por meio da linguagem, manifestamos ideias e conhecimento sobre os mais diversos assuntos, bem como organizamos o pensamento para explicar, aprovar ou condenar, defendendo um ponto de vista.

Nesse sentido, é necessário observar como é tratada e quais avaliações são possíveis a partir dos elementos léxico-gramaticais utilizados em textos veiculados na mídia. Diante disso e com base no sistema de avaliatividade (MARTIN; WHITE, 2005) e suas subcategorias de atitude e gradação, o presente trabalho tem o propósito de realizar uma análise de avaliação na linguagem utilizada em um artigo de opinião acerca do desafio de ser professor no Brasil, veiculado na mídia, em novembro de 2017.

Para tal, buscamos (1) descrever as variáveis de registro (campo, relações e modo) do texto selecionado; (2) identificar os recursos que os sujeitos discursivos empregam para expressar avaliações de atitude, com foco em apreciação, julgamento, sanção social de capacidade e gradação, força, intensificação ou

\footnotetext{
${ }^{1}$ De acordo com o Censo da Educação Superior, publicado pelo Instituto Nacional de Estudos e Pesquisas Educacionais Anísio Teixeira (INEP), o número de matrículas em cursos de bacharelado é aproximadamente quatro vezes maior do que em cursos de licenciatura. Os dados referem-se ao ano de 2013. Disponível em: $<$ http://inepdata.inep.gov.br/analytics/saw.dll?Portal\&PortalPath=\%2Fshared $\% 2$ FGeral $\% 2 \mathrm{~F}$ portal $\% 2 \mathrm{FEduca} \% \mathrm{C} 3 \% \mathrm{~A} 7 \% \mathrm{C} 3 \% \mathrm{~A} 30 \% 20$ Superior $>$ Acesso em 15 janeiro 2018.
} 
quantificação e (3) averiguar de que maneira a avaliatividade contribui para a construção e reiteração de pontos de vista no texto.

Para o desenvolvimento deste trabalho, primeiramente, apresentamos os pressupostos teóricos que embasaram a análise; a seguir, descrevemos a metodologia adotada para analisarmos e discutirmos os dados obtidos. Por fim, nas considerações, concluímos este trabalho, apresentando uma reflexão sobre análise e as discussões propostas.

\section{PRESSUPOSTOS TEÓRICOS}

$\mathrm{Na}$ perspectiva da Linguística Sistêmico-Funcional (doravante LSF), a linguagem é um fenômeno social, concebida como um processo sociossemiótico de produção de significados (HALLIDAY; HASAN, 1985, p. 3), por meio da qual interagimos ao realizarmos trocas significativas nos contextos diversos nos quais nos inserimos. Essa produção de significados no contexto social se realiza, primeiramente, por meio de elementos léxico-gramaticais em textos. Texto, por sua vez, é um processo contínuo de escolhas semânticas, "um movimento através de uma rede potencial de significado" (ibid, p. 10). Nesse sentido, segundo Halliday e Hasan (1985) é um processo que relaciona a linguagem com o todo e pressupõe um olhar para além das palavras e estruturas para interpretá-lo.

Ao conceber a linguagem como um sistema e o texto como um processo que relaciona a linguagem com o todo (HALLIDAY; HASAN, 1985), Martin e White (2005), preocupados com as interações entre escritores e falantes e a construção do texto e seu significado, dedicaram-se a estudar o sistema de avaliatividade, determinando-o como um sistema de construção de significados interpessoais, desenvolvido a partir dos princípios teóricos da LSF, composto por três subsistemas que operam conjuntamente, sendo eles: atitude, engajamento e gradação (MARTIN; WHITE, 2005).

A avaliatividade é um dos três principais recursos semânticos do discurso que interpretam o significado interpessoal, juntamente com o envolvimento e a negociação (ibid, p. 34). O subsistema atitude diz respeito à expressão da emoção do falante/escritor, da ética e da estética que correspondem a afeto, julgamento e apreciação respectivamente. O nível de participação e envolvimento do falante em relação ao que está sendo dito diz respeito ao subsistema de engajamento e considera as múltiplas e diferentes vozes que podem ser convocadas para construir a argumentação de um texto. Nesse caso, com engajamento, podemos ter a contração (contraposição e proposição) ou a expansão (atribuição e entretenimento) dialógica. Finalmente, complementando os subsistemas temos a gradação, através da qual se pode intensificar ou atenuar atitudes e engajamentos.

De acordo com CABRAL (2007), a metafunção interpessoal da linguagem pode indicar como os locutores do texto aprovam ou desaprovam os seres e os

\footnotetext{
${ }^{2}$ No original: "A movement though the network of meaning potencial" (HALLIDAY; HASAN, 1985, p. 10).
} 
fatos, construindo a identidade de seus leitores/ouvintes na intenção de persuadilos de suas crenças e opiniões. Por isso, ao buscarmos identificar manifestações de juízos e opiniões, é necessário nos voltarmos, primeiramente, para a interpessoalidade.

Nesse sentido, o componente interpessoal é a linguagem como modo de ação, e a realidade consiste tanto no que fazemos quanto no que pensamos. (HALLIDAY; MATTHIESSEN, 1999, p. 523). Segundo esses autores, todo o diálogo é um processo de troca, e o falante, a todo momento, está promulgando uma relação interpessoal. Os significados interpessoais tendem a ser construídos ao longo do discurso, pois se relacionam com o todo e não apenas com alguns elementos.

Partindo desses significados, neste trabalho, interessa-nos, particularmente, o subsistema de atitude, por meio do qual se faz possível compreender os modos como uma pessoa, coisa, situação, ação, evento ou estado são vistos, possibilitando uma avaliação positiva ou negativa do enunciado, para averiguar quais avaliações são realizadas em relação ao professor e sua prática pedagógica. Buscamos verificar, também, como se dá, no texto, o uso da gradação que, juntamente com a atitude, atua de forma complementar para corroborar as opiniões expostas. A gradação funciona com dois eixos de escalabilidade, um de acordo com quantidade ou intensidade e outro de acordo com a prototipicidade e a precisão das categorias semânticas. Assim, a gradação pode dar-se por meio do que Martin e White (p. 37) denominam "força" e "foco". O foco é aplicado quando há categorias não escalonáveis, as quais não são claramente delimitadas por não serem graduáveis. Já as categorias passíveis de serem escalonadas podem ser verificadas em quantidade e graus de intensidade por meio da força. A avaliação do grau de intensidade de qualidades e processos é denominada "intensificação".

As intensificações dividem-se em duas classes léxico-gramaticais amplas "isoladas" e "infundidas". A distinção é ativada se o aumento ou redução de escala é realizado por um item individual isolado, que somente, ou pelo menos primariamente, executa a função de definir o nível de intensidade, ou se o sentido da escala ascendente ou decrescente é fundido com um significado que serve para alguma outra função semântica ${ }^{3}$ (ibid, p. 141).

Tendo por base essa fundamentação teórica, delineamos a metodologia empregada na análise do texto em foco.

\footnotetext{
${ }^{3}$ Tradução nossa. No original: "The assessment of degree of intensity of qualities and processes is termed 'intensification'. Intensifications divide into two broad lexicogrammatical classes - 'isolating' and 'infusing'. The distinction turns on whether the up-scaling/down-scaling is realised by an isolated, individual item which solely, or at least primarily, performs the function of setting the level of intensity, or whether the sense of up/down-scaling is fused with a meaning which serves some other semantic function" (MARTIN; WHITE, 2005, p. 141).
} 


\section{METODOLOGIA}

Para a realização deste trabalho, inicialmente, realizamos uma busca por artigos de opinião publicados no site da Revista Veja Online, mais especificamente na seção Educação em Evidência, em novembro de 2017. Essa seção destina-se à publicação de textos que abordam diversos aspectos relacionados à temática de educação.

$\mathrm{O}$ texto selecionado tem por título Ainda sobre os desafios de ser professor - Como avaliar a qualidade de um professor? E como atrair e formar professores de qualidade em um país como o Brasil ${ }^{4}$, de autoria de João Batista Oliveira, publicado em 27/11/2017, o qual promove uma discussão sobre questões educacionais e possíveis soluções para elas. Após o processo de seleção do corpus, prosseguimos com a análise, determinando os procedimentos necessários.

\subsection{Procedimentos de análise}

Para a análise do corpus, primeiramente apresentamos uma breve contextualização com dados referentes ao autor do texto e ao veículo de publicação. Na sequência, realizamos uma análise contextual, descrevendo as variáveis de registro (campo, relações e modo) da LSF. Posteriormente, classificamos e analisamos os elementos léxico-gramaticais que envolvem o sistema de avaliatividade, considerando suas subcategorias de atitude (apreciação e julgamento - sanção social e estima social) e gradação (força - quantificação e intensificação).

Por fim, buscamos promover uma discussão reflexiva sobre o tema, tendo por base os dados alcançados na análise. Ressaltamos, ainda, que para melhor organizá-la, destacamos os excertos utilizados em itálico, identificados por \# ou em caixas com os elementos léxico-gramaticais avaliativos em negrito.

\section{ANÁLISE E DISCUSSÃO DOS DADOS}

Nesta seção propomos concretizar a análise do artigo de opinião selecionado. Para isso, iniciamos com uma breve contextualização acerca do autor e do veículo em que foi publicado.

\footnotetext{
${ }^{4}$ Disponível em: $<$ https://veja.abril.com.br/blog/educacao-em-evidencia/ainda-sobre-osdesafios-de-ser-professor-no-brasil/> Acesso em 18 jan. 2018.
} 


\subsection{Breve contextualização}

A Revista Veja, fonte do artigo de opinião selecionado para esta análise, possui versão online, na qual são compartilhados textos com foco em diferentes assuntos tais como educação, saúde, política, entretenimento, ciência, economia e outros relacionados a temas relevantes na sociedade. Cada um desses temas é abordado em um espaço específico, organizado em seções no site. Um exemplo disso é a seção com o título Educação em Evidência, na qual são compartilhados textos sobre o panorama educacional.

$\mathrm{O}$ autor do artigo selecionado para este trabalho é João Batista Araújo e Oliveira, doutor em pesquisa educacional e autor de diversos livros sobre o tema 5 . Segundo o Instituto Milenium ${ }^{6}$, é considerado referência nacional em educação. Em sua trajetória de pesquisa e atuação, foi professor, pesquisador, consultor e ocupou cargos executivos em organismos nacionais e internacionais. Como secretário-executivo do MEC (1995), idealizou o programa Acelera Brasil, que visa acelerar e corrigir o fluxo escolar, com o apoio do Instituto Ayrton Senna. Na atualidade é fundador e presidente do Instituto Alfa e Beto, organização não governamental promotora de políticas práticas de educação, que prioriza a alfabetização.

Possui vários livros publicados, tais como: A Pedagogia do sucesso (Saraiva, 2001), A Escola vista por dentro (Alfa Educativa, 2002), ABC do alfabetizador (Alfa Educativa, 2005), Aprender e ensinar (Alfa Educativa, 2006), Reforma na educação: por onde começar? (Alfa Educativa, 2006), Usando textos na sala de aula: tipos e gêneros textuais (Alfa Educativa, 2006), Alfabetização de crianças e adultos: novos parâmetros (Alfa Educativa, 2007).

Para dar continuidade a este trabalho, a seguir realizamos a análise contextual, descrevendo as variáveis de registro do texto.

\subsection{Análise contextual do artigo de opinião}

Para organizar a análise de contexto, descrevemos as variáveis de registro de campo, relações e modo. Iniciamos com a variável de campo e identificamos que o texto é de opinião, no qual o autor, João Batista Oliveira, que também é professor, discute sobre os desafios de ser professor no Brasil. Ao longo de seu texto, cita quatro indicadores que permitem aferir qualidade ao professor e propõe-se a responder a três questões sobre o tema.

\footnotetext{
${ }^{5}$ Disponível em: $<$ http://buscatextual.cnpq.br/buscatextual/visualizacv.do? $\mathrm{id}=\mathrm{K} 4765925 \mathrm{~A} 8>$. Acesso em 18 janeiro 2018

${ }^{6}$ Disponível em: $<$ https://www.institutomillenium.org.br/author/joao-batista-oliveira/> Acesso em 20 dezembro 2017
} 
\# Neste post, tentaremos responder três perguntas: (1) em que consiste a qualidade do professor, (2) como formar e (3) como atrair professores de qualidade em um país como o Brasil. \# A qualidade do professor é aferida por quatro indicadores.

Nesse excerto, podemos observar as perguntas norteadoras a que o autor busca responder e a oração que destaca os quatro indicadores para a qualidade do professor. Quanto à variável de registro relações, podemos perceber a função da fala de dar informações, a partir do uso de orações declarativas, que determinam proposições. $\mathrm{O}$ autor, em determinados momentos, assume um posicionamento de participante do texto (\#Neste post, tentaremos responder três perguntas ...). Com base nisso, foi possível identificar as seguintes interações: 1) do autor com a pessoa que está sendo enfocada no texto, o professor, apresentando distância social média, pois este pode ou não ser um leitor e, como tal, possui o direito de fazer comentários na própria seção do site onde foi publicado o texto, se assim desejar; 2) do autor com o leitor do texto, com distância social média; 3) do autor com a comissão editorial do site, com distância social próxima, pois para publicar o texto, subentende-se que ambos interagem no processo de publicação, visto que é uma revista de grande circulação, tanto na modalidade digital, quanto na impressa.

Em relação à variável de registro de modo, destacamos que o texto é apresentado na forma escrita e publicado em um canal virtual, um site de uma revista de grande circulação no país. A linguagem é típica de texto de opinião, fornecendo dados sobre o assunto e argumentos para defender uma tese; usa o tempo presente e a primeira pessoa do plural (nós). Utiliza, também, a linguagem visual (não verbal), pois há uma imagem representando uma professora diante de seus estudantes, a qual faz parte da publicação do texto.

No excerto que segue, percebemos o uso da primeira pessoa do plural.

\# Neste post, tentaremos responder três perguntas (...) \# A maioria dos nossos professores de séries iniciais situa-se no decil inferior da distribuição nas notas do ENEM. (...) \# Trataremos disso no próximo post (...)

Nesse exemplo, o autor parece, ainda, dialogar com o seu leitor e inclui-se como um participante do texto ao usar \# nossos professores.

Dando continuidade à análise, na sequência enfocamos os elementos léxico-gramaticais avaliativos.

\subsection{Análise e discussão dos dados, com base no sistema de avaliatividade}

A análise do artigo de opinião em foco tem por base as subcategorias de atitude e gradação do sistema de avaliatividade, proposto por Martin e White (2005). Primeiramente, o autor faz algumas conjecturas sobre a qualidade do professor e sua relação com o sucesso escolar do aluno, enfatizando um como consequência do outro e vinculando tal afirmação apenas ao contexto escolar. 
Em vista disso, destacamos que o autor, João Batista Araújo e Oliveira, dá início ao seu texto, com base em três questionamentos, sendo eles: 1) em que consiste a qualidade do professor; 2) como formar e 3) como atrair professores de qualidade.

Ao longo do texto, o autor busca responder ao primeiro questionamento e, para isso, defende quatro indicadores (\# A qualidade do professor é aferida por quatro indicadores), que julga relevantes para determinar a qualidade do professor no Brasil, problematizando-os. O Quadro 1 sumariza esses indicadores.

Quadro 1- Indicadores referentes à qualidade do ensino

1) o nível de qualidade da formação dos professores;

2) o preparo dos professores para o ensino de uma turma ou disciplina específica;

3) a capacidade dos professores para a prática de usar estratégias eficazes de ensino;

4) o desempenho dos alunos desses professores, a curto e longo prazo.

Fonte: criado pelas autoras com base nos dados do texto analisado.

Ao determinar esses indicadores, o autor utiliza elementos léxicogramaticais avaliativos, os quais demonstram apreciação, pois conferem reação às coisas, sua composição e seus valores (MARTIN; WHITE, 2005, p. 56). Os exemplos abaixo buscam comprovar essa assertiva.

\# A qualidade do professor é fator decisivo para o sucesso dos alunos

\# No Brasil, um bom indicador seria a nota do ENEM.

\# (...) a capacidade prática de o professor usar estratégias eficazes de ensino em sala de aula.

\# Por exemplo: para um professor com turmas do $6^{\circ}$ ao $9^{\circ}$ ano é mais importante conhecer a fundo os conteúdos deste período.

\# O terceiro indicador se refere à capacidade prática. (...)

\# mas raramente eles situam-se acima do nível médio de desempenho.

Nesses excertos encontramos termos como decisivo, bom, eficazes, importante, prática e médio, evidenciando apreciação para fator, indicador, estratégias, conhecer os conteúdos, capacidade e nivel, respectivamente. As apreciações em questão apresentam caráter positivo, o que se justifica à medida que são atribuídas a elementos que fazem parte do sistema escolar e da atividade do professor. Com isso, o autor busca destacar que o fator decisivo é a qualidade do professor e reconhece a importância dos indicadores de nota do aluno, das estratégias utilizadas pelo professor, do conhecimento do conteúdo que deve ser trabalhado e da sua capacidade de colocar em prática metodologias adequadas.

De acordo com Martin e White (2005), o julgamento pode estar relacionado à estima ou sanção social. No caso do texto analisado, refere-se à primeira (estima social), fazendo o julgamento de capacidade. Nesse sentido, 
encontramos elementos léxico-gramaticais que evidenciam essa afirmação, como por exemplo os que se apresentam nos excertos que seguem.

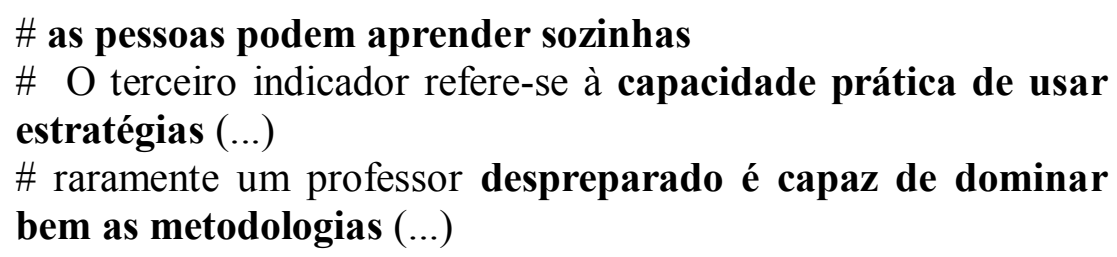

Conforme os exemplos acima, há um julgamento de capacidade quando o autor indica que as pessoas podem aprender sozinhas, pois são capazes; o professor deve possuir a capacidade de pesquisar estratégias de acordo com as demandas de seu contexto escolar; ou, ainda, um professor despreparado não é capaz de utilizar com confiança as metodologias de ensino. Observamos que nos dois primeiros exemplos, o autor atribui capacidade positiva e, no último, negativa, enfatizando a relevância da formação do professor, caso contrário, a falta de preparo e conhecimento refletirá negativamente na prática de sala de aula.

Neste outro fragmento percebemos não só o julgamento de capacidade negativa, como também apreciação.

\# A maioria dos nossos professores de séries iniciais situa-se no decil inferior da distribuição nas notas do ENEM.

Ao afirmar que o professor das séries iniciais se encontra no decil inferior das notas do ENEM, o autor utiliza o termo inferior para atribuir capacidade negativa ao professor desse nível escolar e, ao mesmo tempo, atribui apreciação. Além da avaliação inscrita diretamente no discurso por meio do léxico inferior, evidenciando capacidade negativa de forma explícita, é possível também inferir significados que invocam uma avaliação depreciativa da capacitação profissional do professor. $\mathrm{O}$ autor, ao fazer suas considerações, refere-se à maioria dos professores, demonstrando alto grau de quantificação e, portanto, revelando, sua opinião desfavorável às condições profissionais dos professores.

O autor, ainda, reconhece o \# grande desafio (apreciação) para melhorar a carreira de professor no Brasil, indicando que \# ficamos presos no primeiro indicador (capacidade negativa para reagir, fazer algo). Isso também ocorre quando argumenta que \# as autoridades educacionais brasileiras vêm tentando, sem sucesso (capacidade negativa) diferentes estratégias (apreciação) de "capacitação e formação em serviço" (aspas do autor).

Observamos, ainda, evidências linguísticas de gradação (intensificação), quando o autor revela que: \# (...) Tudo isso é muito (intensificação) mais importante (intensificação) do que obter graus mais avançados (intensificação) como mestrado e doutorado (...); reforça, ainda, que \# dominar bem (intensificação) as metodologias (...) é algo importante, que confere qualidade ao professor.

A gradação de intensificação reforça o argumento do autor de que a preparação profissional pré-serviço e o conhecimento específico do conteúdo que se ensina são fatores primordiais para determinar a qualidade do professor. 
A gradação quantificação é evidenciada quando o autor aborda os dados referentes às pesquisas, tais como: os 30\% melhores são recrutados; os 30\% melhores do ensino médio; um gigantesco desafio; cerca de $\mathbf{5 0 \%}$ das pessoas (...). Tanto no uso de gradação de quantificação, quanto de intensificação, fica implícita a comparação entre os professores brasileiros e de outros países; e o fato de o Brasil não ser educacionalmente desenvolvido está diretamente ligado à má formação dos professores, apesar das tentativas do governo. Além disso, expressa incredulidade em relação à eficácia dos métodos governamentais para solucionar o problema e o desperdício econômico que tais medidas representam.

Ao mesmo tempo em que destaca os indicadores para aferir a qualidade do professor, constituindo-se como um desafio a ser enfrentado, Oliveira propõe sugestões de possibilidades de resolução para os problemas apontados, respondendo a sua última questão de como atrair professores de qualidade. Dessa forma, defende que uma alternativa seria \# atrair jovens entre os melhores do ensino médio, ou \# já formados e com perfil, \# com formação de qualidade, ou seja \# pessoas talentosas (capacidade positiva) e bem formadas (gradação intensificação) têm mais chances (gradação quantificação) de se tornar profissionais de boa qualidade.

Um primeiro passo consistiria em atrair jovens situados entre os $30 \%$ melhores do ensino médio - com notas em torno de 700 pontos no ENEM. Uma alternativa é atrair jovens já formados com esse perfil e que queiram mudar de profissão.

No fragmento anterior, a sugestão do autor para elevar o nível dos profissionais da educação nos permite inferir que os atuais professores provêm de grupos inferiormente capacitados, de acordo com os índices do ENEM. Desse modo, os professores são considerados despreparados, pois antes mesmo de passarem por uma formação, os jovens que optam por essa profissão já não apresentam um bom nível de conhecimentos. Sendo assim, o autor defende a ideia de que a falta de qualidade profissional dos professores é uma questão que precede o ensino superior.

Outra sugestão para resolver o problema do desafio de ser professor, conferindo-lhe qualidade, é citada quando o autor faz uma apreciação das escolas, as quais facilitariam esse processo, se apresentassem determinadas características, conforme destaca o excerto que segue.

\section{\# escolas bem organizadas, de boa qualidade e sob supervisão de professores experientes e competentes no ensino de estratégias comprovadamente eficazes de manejo de classe de diferentes faixas etárias e ensino de disciplinas específicas.}

Nesse fragmento, que está ao final do texto, o autor argumenta que ter escolas com tais características é \# um gigantesco (apreciação) desafio, no caso brasileiro, tanto pela falta de pessoas experientes para servir como tutores e pela falta de escolas em condições de servirem como plataformas adequadas quanto, sobretudo, pela falta de convicção e conhecimento das evidências sobre o que 
efetivamente funciona. Nesse caso, a recorrência da palavra falta sugere apreciação dos obstáculos para a implementação das alternativas sugeridas por ele, colocando a situação educacional brasileira como uma grande problemática a ser resolvida a longo prazo.

Ao nos referirmos ao termo falta e sua recorrência, podemos identificar a avaliação de capacidade negativa, visto que o autor enfatiza a ausência de pessoas experientes e de escolas e plataformas adequadas para o preparo do aluno. Com isso, invoca uma avaliação depreciativa acerca do sistema educacional brasileiro como um todo e coloca em dúvida a capacitação do professor para trabalhar em um sistema que não funciona adequadamente para atender às necessidades do aluno e às demandas da sociedade.

Por fim, como quarto e último passo para conferir qualidade ao professor e, assim, cumprir com o desafio da profissão e formar estudantes bem-sucedidos, o autor elege \# a remuneração atraente (apreciação) para o professor, como um ponto importante, o qual merece, segundo ele, uma discussão própria, em uma outra postagem, subentendendo um outro texto (\# Trataremos disso no próximo post). Observamos ainda que a escolha do autor em mencionar a remuneração, somente no final do texto, sugeriria que ela não ocupa um lugar de prioridade entre as medidas que possam aferir melhor qualidade ao professor.

Diante da análise de alguns dados e evidências linguísticas do texto, passamos a seguir para as considerações finais deste trabalho.

\section{CONSIDERAÇÕES FINAIS}

O sistema de avaliatividade (MARTIN; WHITE, 2005) nos permite explorar diferentes textos para analisar os posicionamentos e perspectivas apresentadas sobre diferentes assuntos. No caso deste trabalho, tomamos por foco de nossa análise um artigo de opinião e buscamos verificar a presença de evidências léxico-gramaticais de avaliatividade. $O$ texto apresenta uma organização, iniciada por questionamentos sobre a profissão de professor, os quais são respondidos no decorrer do desenvolvimento e seguidos de sugestões para melhor resolver os impasses na qualificação dos professores. Ao observarmos como se dá a exposição dos indicadores que demonstram a qualificação dos profissionais da educação e os elementos necessários para que ela ocorra, foi possível averiguar, no texto selecionado, a presença marcante dos subsistemas atitude e gradação.

No decorrer da análise, evidenciou-se o uso de apreciação e julgamento acrescidos de gradação. As evidências linguísticas demonstraram um grande uso de apreciações, que se justificam pela provável intenção do autor de qualificar, positiva ou negativamente, ao tratar dos indicadores e construir uma visão de quais elementos são necessários para a qualificação do professor. Além disso, por meio do julgamento de estima social - capacidade, o professor passa a ser avaliado e, por vezes, criticado negativamente no que diz respeito a sua capacitação. 
Complementando as observações sobre a capacitação do professor, as gradações de intensificação reforçam a opinião do autor sobre o que é mais relevante para sua qualificação. Além disso, as gradações de quantificação aparecem como forma de referendar as opiniões, utilizando-se dos dados quantitativos para ajuizar a qualificação dos professores ou a falta dela. Desse modo, foi-nos possível apreender o quanto a utilização dos subsistemas de avaliatividade, neste caso especificamente, a atitude, por meio do julgamento e da apreciação, e a gradação ratificam o ponto de vista do autor sobre a capacitação profissional do professor e como ela repercute no ensino.

Destacamos, ainda, que esta análise possibilita a ampliação de pesquisas sobre assunto abordado, por meio de uma comparação com outros textos acerca desta temática, publicados no site Revista Veja Online e pelo mesmo autor, com o intuito de compor um todo significativo envolvendo professor, qualidade, ensino, escolas e indicadores de notas.

\section{REFERÊNCIAS}

CABRAL, Sara Regina Scotta. A mídia e o presidente: um julgamento com base na teoria da valoração. Tese (Doutorado em Letras, Estudos Linguísticos) Universidade Federal de Santa Maria, 2007.

HALLIDAY, Michael; HASAN, Ruqaiya. Language, context and text: aspects of language in a social-semiotic perspective. Austrália: Deakin University, 1985.

HALLIDAY, Michael; MATTHIESSEN, Christian. Construing Experience Through Meaning: a language approach to cognition. Londres/Nova Iorque: Continnuum, 1999.

$\overline{\text { Routledge, }} 2014$.

An introduction to functional grammar. $4^{\mathrm{a}}$ ed. Nova Iorque:

MARTIN, James; WHITE, Peter. The language of Evaluation: appraisal in English. Nova Iorque: Palgrave MacMillan, 2005.

OECD. Low-Performing Students: Why They Fall Behind and How to Help Them Succeed, PISA, OECD Publishing, Paris. Disponível em: $<$ www.oecdilibrary.org/education/low-performing-students_9789264250246-en $>$ Acesso em 15 janeiro 2018

OLIVEIRA, João Batista. "Ainda sobre os desafios de ser professor no Brasil". Veja online. Disponível em: $<$ https://veja.abril.com.br/blog/educacao-emevidencia/ainda-sobre-os-desafios-de-ser-professor-no-brasil/> Acesso em 18 janeiro 2018

PEREIRA JUNIOR, Edmilson Antônio. Condições de trabalho docente nas escolas de educação básica no Brasil: uma análise quantitativa. 2016. 230 f. Tese 
(Doutorado em Educação) - Universidade Federal de Minas Gerais. Belo Horizonte. 2016.

Ana Paula Carvalho Schmidt

Ana-gcarvalho@hotmail.com

Anidene Siqueira Cecchin Anicecchin@gmail.com

Nédilã Espindola Chagas Nedila.espindola.chagas@,gmail

Sara Regina Scotta Cabral Sara.scotta.cabral@,gmail.com

Recebido em: 28 fev. 2018

Aceito em: 26 maio 2018

Publicado em: 19 ago. 2018 